\title{
Aplikasi Konsep Islami Nuansa Turki Utsmaniyah pada Interior Madrasah mambaul Hasan Al-Misbah Paiton, Probolinggo
}

\author{
Sylviana Qurrata A'yun dan Nanik Rachmaniyah \\ Departemen Desain Interior, Fakultas Teknik Sipil dan Perencanaan, Institut Teknologi Sepuluh Nopember (ITS) \\ e-mail: sylvianaqurrataayun@gmail.com
}

\begin{abstract}
Abstrak-Masuknya modernisme di Indonesia tanpa filtrasi yang baik karena perkembangan teknologi yang tak terkontrol menyebabkan penurunan moral pada kalangan pemuda-pemudi Indonesia. Agama islam memiliki tiga aspek pokok yang harus diperhatikan, yaitu aspek Aqidah (keimanan), aspek Syariah (norma dan hukum) dan aspek Akhlak (moral dan budaya). Penyeimbangan ketiga aspek tersebut akan sangat menentukan kemajuan umat islam, maka dibutuhkan fasilitas yang mampu mengakomodasi ketiganya, yaitu fasilitas pendidikan atau sekolah. Sekolah islam atau madrasah dianggap mampu menciptakan generasi yang beriman dan bermoral atau berakhlak mulia, dengan berlandaskan A-Quran dan AsSunnah. Konsep desain islami diterapkan pada sekolah dengan nuansa turki utsmaniyah sebagai lambing kejayaan islam. Hal ini diharapkan dapat member kesan positif dan membangun kebiasaan-kebiasaan baik sebagai seorang muslim.
\end{abstract}

Kata Kunci-Sekolah, Islami, Turki Utsmaniyah.

\section{PENDAHULUAN}

$\mathrm{D}$ I Indonesia, tercatat bahwa mayoritas masyarakatnya merupakan pemeluk agama islam, akan tetapisaat ini umat islam di Indonesia maupun dunia sedang mengalami penurunan kualitas. Hal ini disebabkan oleh paham sekulerisme yaitu memisahkan antara ibadah dan muamalah sehingga cenderung hanya mengarah pada urusan dunia dan meninggalkan akhirat atau sebaliknya. Melalui hadistnya, Nabi Muhammad mengatakan bahwa menuntut ilmu itu wajib bagi semua Muslim dan Muslimah. Namun, di dalam hadist tersebut Rasul tidak menyebutkan secara spesifik ilmu apa yang perlu kita pelajari atau tidak boleh kita pelajari. Akibat dari pemahaman sekuler, fasilitas pendidikan yang semula berfungsi sebagai tempat untuk menuntut ilmu dunia dan agama beralih fungsi hanya sebagai tempat belajar ilmu dunia saja. Padahal keduanya sangat diperlukan dalam kehidupan bermasyarakat.

Sekolah Islam merupakan salah satu fasilitas pendidikan yang dianggap mampu menciptakan anak didik yang tak hanya pandai dalam hal duniawi tetapi juga dituntut untuk tetap belajar ilmu agama melalui kegiatan-kegiatan keagamaan di sekolah. Untuk mendukung terjalinnya kebiasaan-kebiasaan islami oleh anak didik, sekolah perlu melakukan beberapa treatment. Banyak hal yang dapat dilakukan untuk mendidik anak didik menjadi muslim dan muslimah berakhlak, salah satunya dengan tetap menjaga konsep keislaman pada lingkungan sekolah.

Untuk itu, dilakukan penelitian tentang tema konsep islami pada sekolah, baik bangunan maupun ruangannya. Dengan mempertimbangkan segi warna, bentuk dan tete ruang yang baik untuk menunjang terciptanya kenyamanan bagi anak didik. Untuk mendukung konsep ini, nuansa juga perlu dibangun untuk menciptakan kesan positif yaitu nuansa turki utsmaniyah sebagai simbol kejayaan islam. Penerapan konsep islami dan nuansa turki utsmaniyah ini diaplikasikan pada elemen bangunan seperti dinding, lantai, plafon, elemen estetis/pemanis ruang, serta penataan dan pemilihan furnitur pada setiap ruang di sekolah khususnya pada area ruang kelas, ruang perpustakaan dan masjid seklah sebagai pusat ibadah dan kegiatan keagamaan di sekolah.

\section{A. Rumusan Masalah}

1. Bagaimana konsep desain tema islami dan nuansa turki utsmaniyah?

2. Bagaimana aplikasi konsep desain islami dan nuansa turki utsmaniyah?

B. Tujuan

1. Menjabarkan konsep desain tema islami dan nuansa turki utsmaniyah

2. Menerapkan tema islami dengan nuansa turki utsmaniyah ke dalam bangunan sebagai representatif sekolah berbasis islam.

\section{TINJAUAN PUSTAKA}

\section{A. Madrasah Mambaul Hasan Al-Misbah}

Menurut Peraturan Menteri Agama RI Nomor 1 Tahun 1946 dan Nomor 7 Tahun 1950, madrasah adalah tempat pendidikan atau sekolah yang membuat ilmu pengetahuan agama Islam menjadi pokok pengajaran; dan pondok pesantren yang memberikan pendidikan setingkat dengan madrasah (sekolah) (Tim Dirjen Bimbagais Depag, 2003: 22). Sedangkan menurut SKB (Surat Keputusan Bersama) Tiga Menteri 1975, madrasah diartikan sebagai lembaga pendidikan yang menjadikan mata pelajaran pendidikan agama Islam sebagai mata pelajaran dasar yang diberikan sekurangkurangnya $30 \%$, di samping mata pelajaran umum.

Berdasarkan pernyataan di atas dapat diambil kesimpulan bahwa madrasah merupakan sekolah berbasis Islam yang di dalamnya diajarkan ilmu pengetahuan umum dan agama dengan pengetahuan Agama Islam sebagai pokok pengajaran.

Yayasan Pendidikan dan Sosial Mambaul Hasan berlokasi di Jalan Joharan 165 RT/RW: 08/03 Desa Sumberrejo Kecamatan Paiton, Probolinggo 67291. Madrasah Mambaul Hasan Al-Misbah merupakan sebuah yayasan pendidikan dan 
sosial yang berazaskan syari'at islam, pancasila dan UndangUndang Dasar 1945. Yayasan ini bergerak di bidang sosial, kemanusiaan dan keagamaan, mendirikan lembaga pendidikan formal berupa madrasah dan pendidikan nonformal berupa pondok pesantren. Dalam pelaksanaannya, madrasah dan ponpes merupakan satu kesatuan lingkup pendidikan yang saling berkaitan.

\section{B. Konsep Islami Nuansa Turki Utsmaniyah}

Bagi umat muslim, hal terpenting yang ingin di dapatkan pada desain dan dekorasi mereka adalah suasana yang hangat, bersih, indah dan penuh cinta. Islam memiliki kekhasan dalam desain interior, bahkan menurut sejumlah para ahli, islam kaya akan sejarah dunia arsitektur yang khas dan memiliki pengaruh besar terhadap perkembangan dunia arsitektur dan desain interior hingga saat ini. Turki Utsmaniyah merupakan salah satu dari tiga kerajaan besar Islam. Masa Khilafah Utsmaniyah merupakan periode pemerintahan Khilafah Islamiyah terpanjang dan terkuat dengan wilayah kekuasaan terluas dalam sejarah umat Islam. Di masa modern saat ini, wilayah kekuasaannya mencakup 15 negara yang berada di wilayah Timur Tengah, Asia Kecil, dan Eropa. (Petersen: 2002, 216).

Arsitek pada masa Khilafah Utsmaniyah yang paling berpengaruh dalam perkembangan Arsitektur Utsmaniyah adalah Mimar Sinan Aga, bahkan pengaruh teori Mimar Sinan Aga masih dirasakan hingga saat ini, khususnya dalam perancangan arsitektur masjid beraliran Utsmaniyah.

Konsep desain Turki Utsmaniyah mengedepankan konsep simetris dan harmonis. Menurut Yildizlar (2012: 207), arsitektur masjid Utsmaniyah menerapkan prinsip keseimbangan simetris dalam wujud arsitekturalnya yang sangat berkaitan dengan penerapan prinsip desain geometri sebagai pembentuk wujud fisik arsitekturalnya.

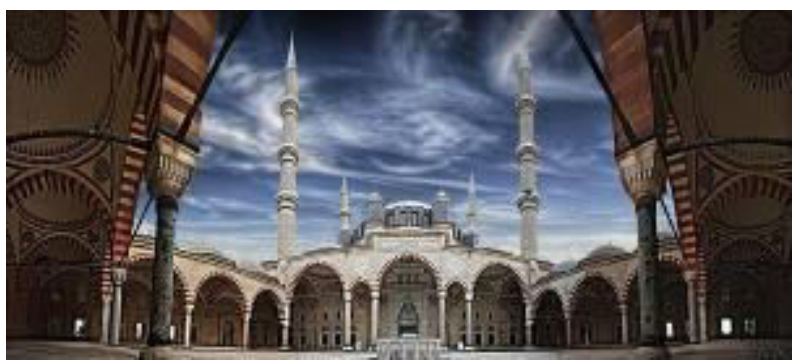

Gambar 1. Konsep Simestris Masjid Selimiye.

Sumber: http://dakwah.org/gallery/displayimage.php?pid=632

Sedangkan elemen ruang dalam arsitektur masjid Utsmaniyah merupakan satu kesatuan membentuk harmonisasi. Penerapan elemen kubah pusat dan semi kubah tidak hanya bertujuan fungsional, namun juga membentuk harmonisasi ruang dalam bangunan. Selain itu, perletakan minaret di sudut bangunan serta jumlah dan tinggi minaret yang digunakan bertujuan pula untuk membentuk harmonisasi yang seimbang. Petersen (2002: 217) menyatakan bahwa monumental merupakan konsep arsitektur masjid Utsmaniyah, walaupun hal tersebut tidak mudah dicapai dengan menggunakan bahan bata dan batu. Namun di sisi lain, hal tersebut menandakan tingginya kemampuan teknik konstruksi di masa Khilafah Utsmaniyah.

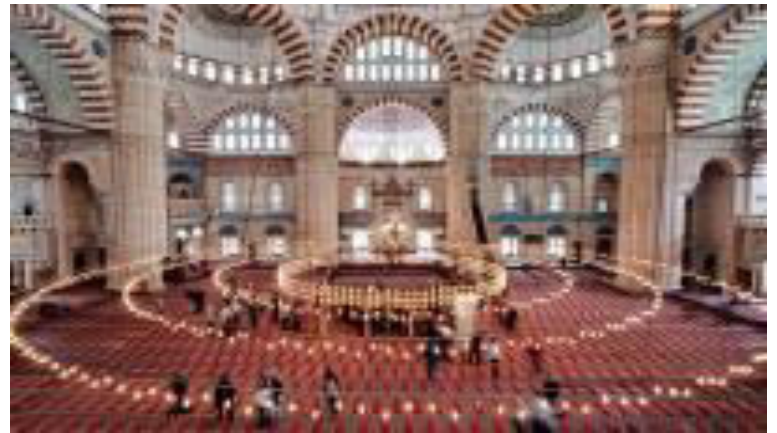

Gambar 2. Konsep Harmonis Masjid Selimiye.

Sumber: pinterest.com

Selain itu, Turki Utsmaniyah memiliki prinsip desain yaitu geometri dan increase in luminosity. Arsitektur masjid Utsmaniyah menurut Yildizlar (2012: 207) menerapkan prinsip desain geometri sebagai pembentuk wujud arsitekturalnya, di mana tradisi ini diperkenalkan oleh Mimar Sinan Aga. Ozgules (2008: 15) menyatakan bahwa, arsitektur masjid Utsmaniyah berhasil memadukan antara dua bentuk geometri yang berbeda, yaitu bentuk persegi (cube) dan bidang lengkung (sphere). Menurut Buckhardt (2009: 156), pada hakikatnya arsitektur masjid Utsmaniyah mengembangkan bentuk dasar persegi dengan kubah pusat sebagai elemen lengkung. Mengenai perpaduan antara bentuk persegi (cube) dan bidang lengkung (sphere) yang merupakan prinsip dalam arsitektur masjid Utsmaniyah, Buckhardt (2009, 156) menyatakan, Penerapan bentuk persegi (cube) dan bidang lengkung (sphere), selain dikarenakan faktor fungsional juga bertujuan sebagai elemen yang merepresentasikan teori yang mendasari arsitektur masjid Utsmaniyah.

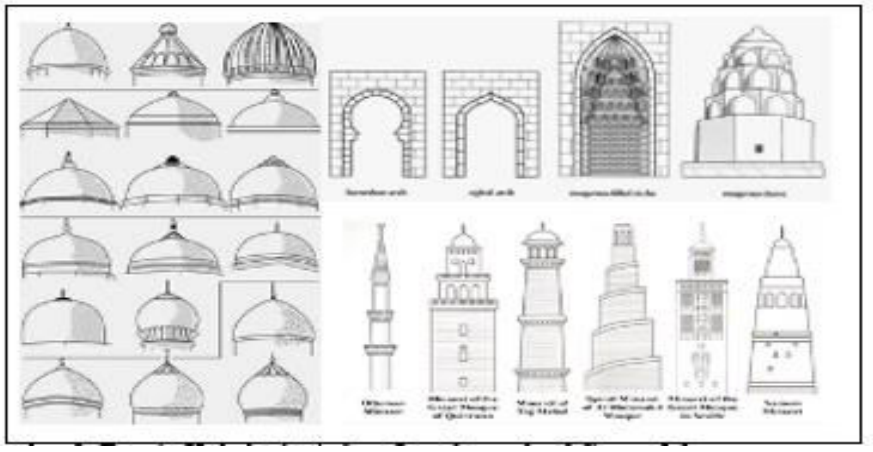

Gambar 3. Desain Kubah, Arsitektur Lengkung dan Minaret/Menara Sumber: http://desain-rumah-idamanku.blogspot.co.id
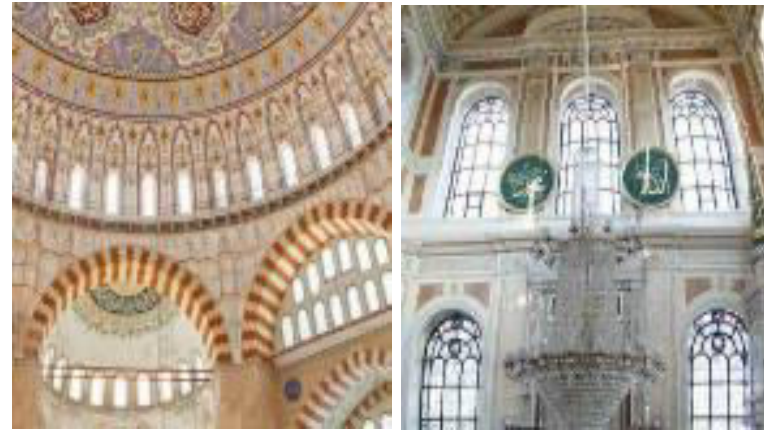

Gambar 4. Aplikasi Prinsip Increase in Luminosity.

Sumber: pinterest.com 


\section{METODE DESAIN}

\section{A. Teknik Pengumpulan Data}

Metode penelitian yang dilakukan meliputi:

- Sumber Data Primer

Sumber data primer diperoleh dari sumber langsung, peneliti melakukan observasi/survey langsung ke tempat objek yang sedang dikaji dan melakukan wawancara dengan responden.

- Sumber Data Sekunder

Pengumpulan data ini dilakukan dengan cara mengumpulkan data yang relevan terhadap topik pembahasan dari berbagai sumber, seperti buku, website, dan studi lain yang berkaitan.

- $\quad$ Studi Literatur

Studi literatur ini diperoleh melalui internet/website berupa artikel atau berita yang terkait dengan topik objek dan bahasan perancangan konsep.

- Studi Pembanding

Studi pembanding bertujuan untuk mendapat referensi data yang bermanfaat dalam proses perancangan.

\section{B. Alur Metodologi Desain}

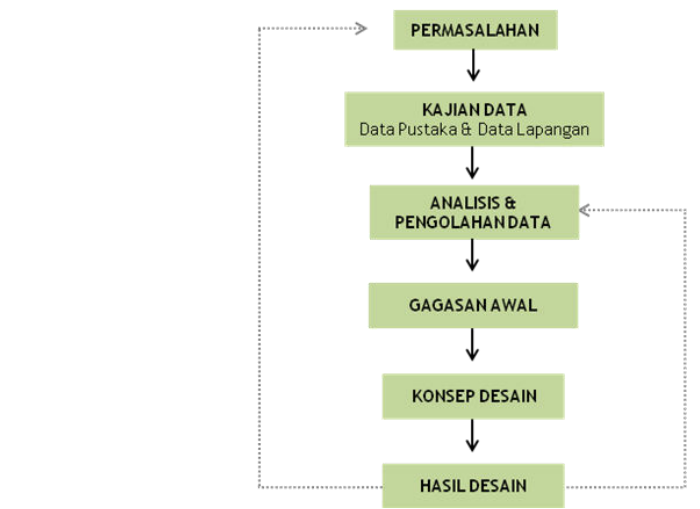

Gambar 5. Alur Metodologi Desain

Sumber: Data Pribadi Penulis

\section{HASIL DAN PEMBAHASAN}

\section{A. Hasil Desain}

1) Konsep Warna
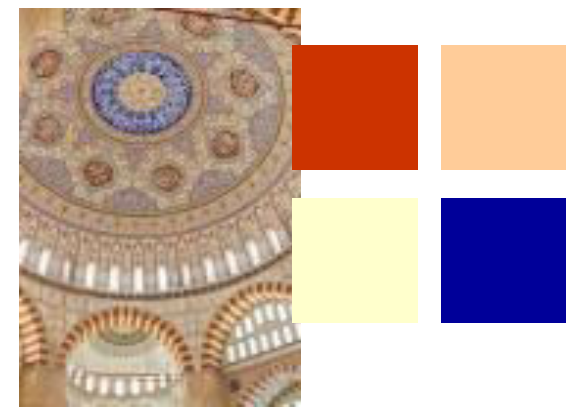

Gambar 6. Tone Warna Masjid Selimiye.

Sumber: https://google.com (2016)

Desain masjid Selimiye menggunakan tone warna merah bata sebagai warna utama dan warna biru sebagai aksentuasi pada beberapa area.

\section{2) Konsep Bentuk dan Motif}
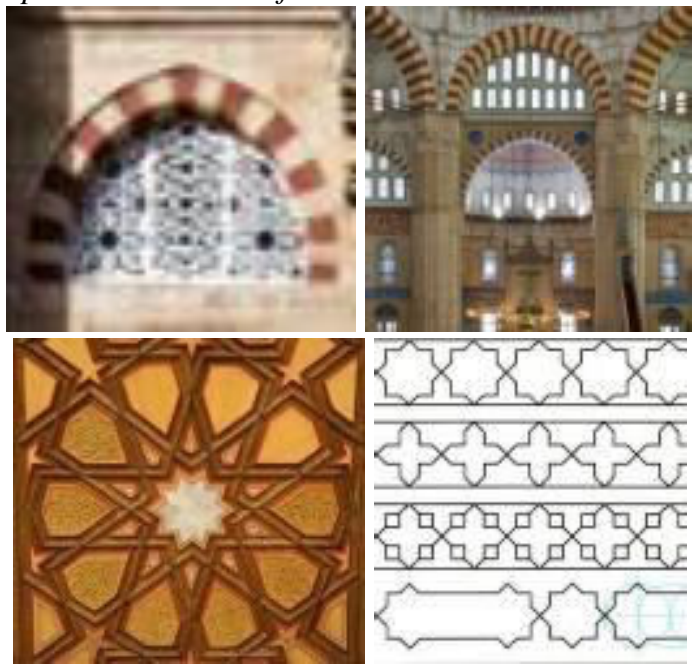

Gambar 7 Konsep Bentuk Masjid Selimiye Sumber: https://google.com (2016)

Bentukan yang khas adalah lengkungan seperti gambar di atas, dengan motif belang merah bata tua dan krem atau gading. Ada pula bentukan geometri khas islam menyerupai bentuk bunga.

\section{3) Konsep Material}

Material yang cocok digunakan untuk ruang/area pada sekolah adalah yang mudah dipindah seperti plastik dan kayu ringan, serta mudah dibersihkan dan tidak susah dalam pemeliharaan.

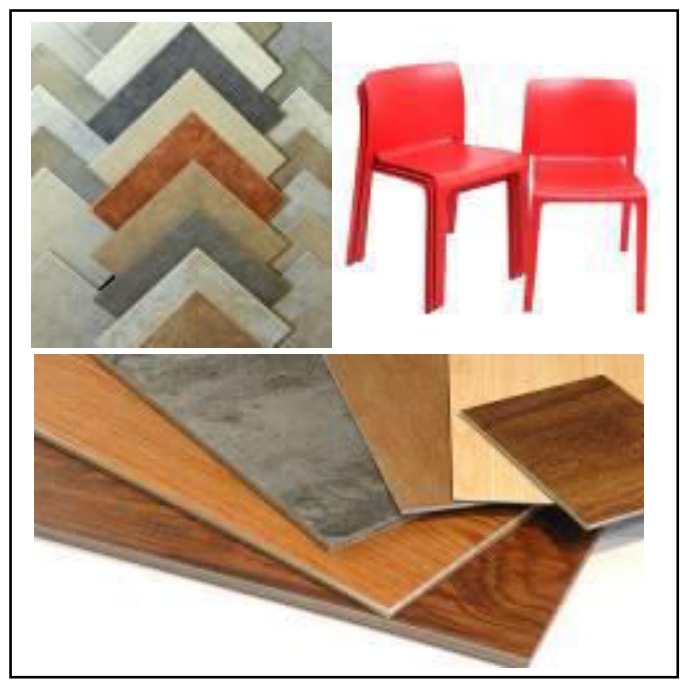

Gambar 8. Konsep Material.

Sumber: https://google.com (2016)

Gambar di atas adalah material yang akan digunakan pada ruangan. Karpet diaplikasikan pada lantai untuk memberi kesan nyaman seperti di rumah dan dapat meredam kebisingan, keramik dapat diaplikasikan pada lantai atau dinding, material plastik digunakan pada furnitur agar mudah dipindah/dibersihkan, material vinyl untuk lantai memberi kesan nyaman dan bersih, kemudian material gypsum diaplikasikan pada plafond an memungkinkan untuk upceiling maupun down-ceiling. Berikut bagan konsep desain 
yang akan diaplikasikan pada perancangan desaini nterior Madrasah.

\section{B. Aplikasi Konsep Desain}

Konsep desain akan diaplikasikan pada tiga ruang terpilih yaitu ruang kelas, ruang perpustakaan dan masjid sekolah. Aplikasi desain berupa penerapan warna dan penerapan bentukan Turki Utsmaniyah sebagai representasi tema islami.

1) Aplikasi pada Ruang Kelas

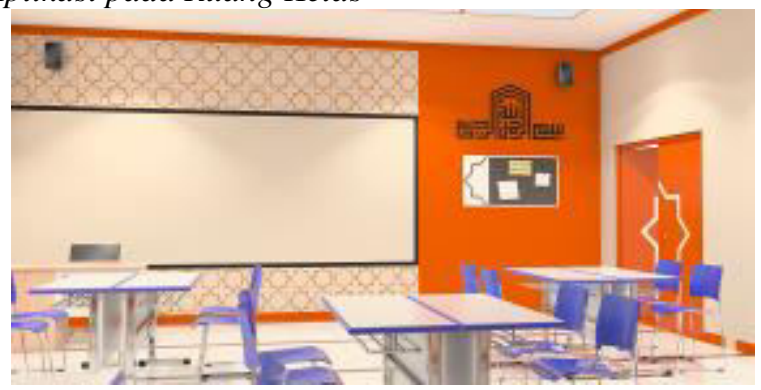

Gambar 9 Aplikasi pada Ruang Kelas 1.

Sumber: Data Pribadi Penulis

Pada ruang kelas aplikasi warna turki utsmaniyah dengan penerapan cat warna krem dan terracotta, serta aplikasi warna biru sebagai aksen warna diterapkan pada warna meja dan kursi siswa dan berada di tengah-tengah ruangan. konsep bentukan turki utsmaniyah terlihat pada detail pintu, dinding bagian depan kelas. Selain itu, terdapat detail kaligrafi sebagai representasi tema islami.

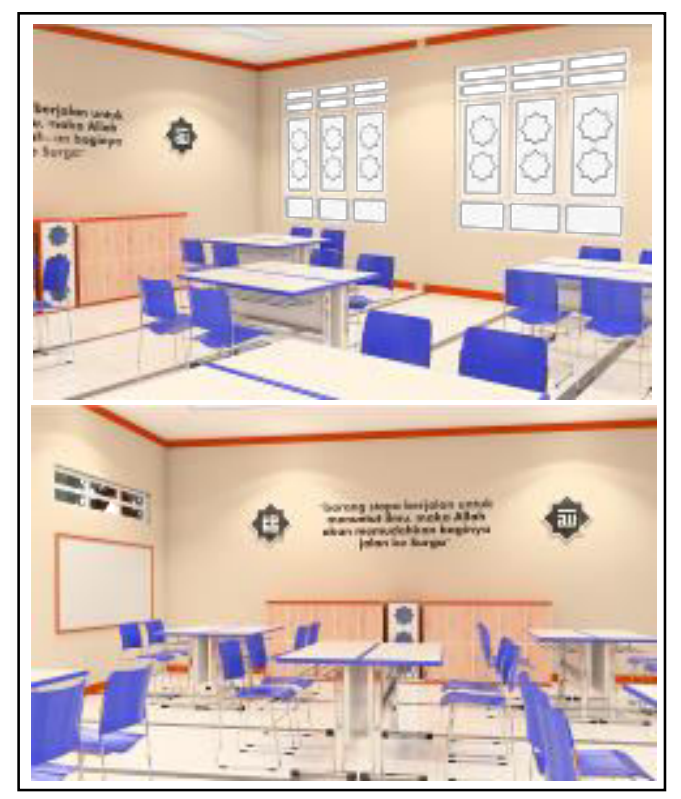

Gambar 10 Aplikasi pada Ruang Kelas 2

Sumber:Data Pribadi Penulis

Selain itu, aplikasi bentukan turki utsmaniyah juga diterapkan pada detail jendela, hal ini juga dimaksudkan agar panas tidak langsung masuk ke ruangan. Hiasan dinding dan storage pada bagian belakang kelas juga merupakan aplikasi bentukan turki utsmaniyah. Bentukannya diselaraskan dengan pintu dan detail jendela untuk menciptakan harmonisasi ruang.

\section{2) Aplikasi pada Ruang Perpustakaan}

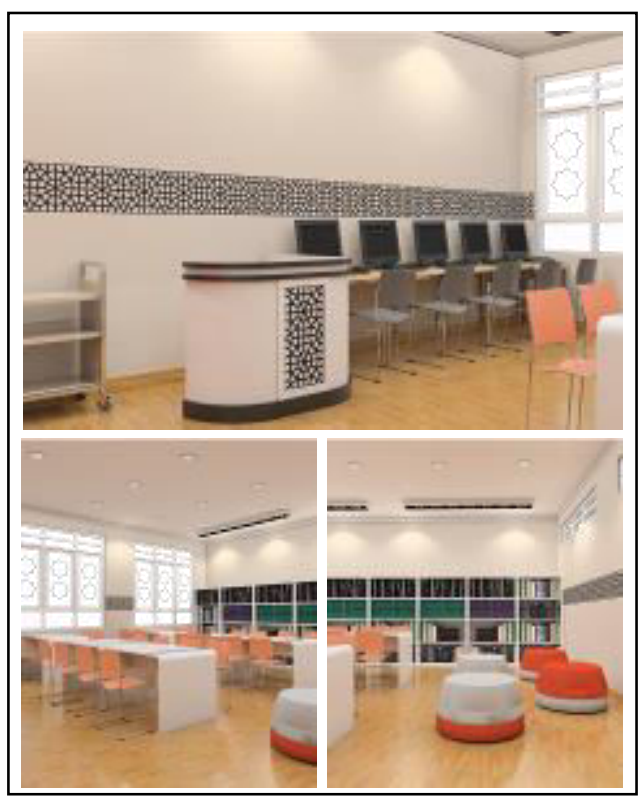

Gambar 11. Aplikasi pada Ruang Perpustakaan.

Sumber: Data Pribadi Penulis

Pada ruang perpustakaan, diterapkan warna krem pada seluruh dinding. Aksen warna terracotta diaplikasikan pada furnitur sofa. Selain itu, kursi baca dipilih warna jingga muda yang senada. Lantai ruang perpustakaan menggunakan parket untuk member kesan nyaman.

Sedangkan bentukan turki utsmaniyah diaplikasikan pada pintu, detail jendela, keramik estetis pada dinding ruangan dan pada meja resepsionis.

\section{3) Aplikasi pada Majid Sekolah}

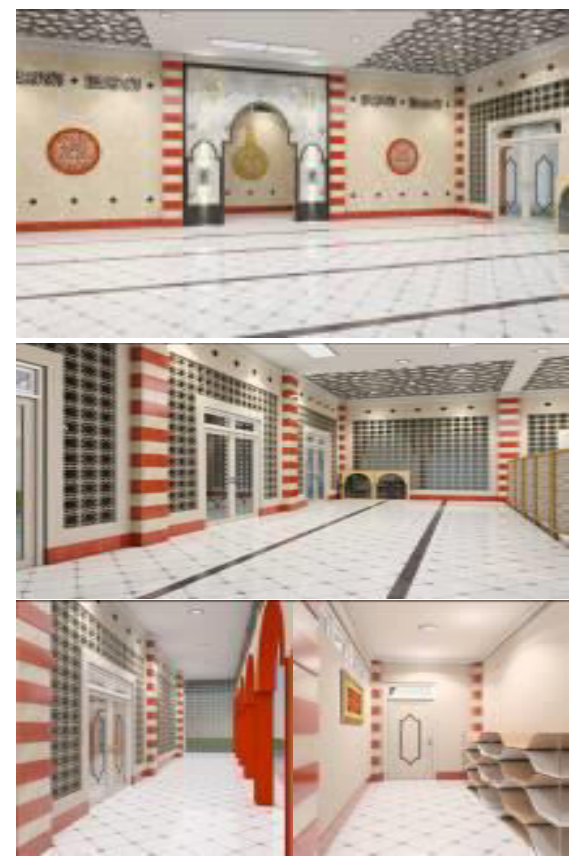

Gambar 12. Aplikasi pada Masjid Sekolah.

Sumber: Data Pribadi Penulis 
Penerapan nuansa turki utsmaniyah sangat terlihat pada masjid sekolah karena masjid merupakan ikon madrasah. Konsep warna terlihat pada warna dinding dan kolom estetis yang menggunakan keramik warna krem dan terracotta dengan teknik pewarnaan berselingan khas turki utsmaniyah.

Sedangkan konsep bentukan terlihat pada setiap detail ruangan seperti dinding loster custom yang tidak hanya berfungsi sebagai hiasan atau representasi desain turki utsmaniyah tetapi juga berfungsi sebagai penghawaan dan pencahayaan alami. Plafon estetis juga menggunakan bentukan geometri islam. Sedangkan detail pintu menerapkan bentukan yang lebih sederhana. Selain itu, konsep bentukan furnitur juga masih satu kesatuan dengan konsep desain islami. Partisi masjid, sebagai pemisah antara shaff putrid dan putra di desain dengan bentukan geometri islam. Selain itu, storage quran dan mukena diambil dari bentuk lengkungan kubah masjid.

\section{KESIMPULAN DAN SARAN}

\section{A. Kesimpulan}

Berdasarkan pembahasan di atas, berikut beberapa kesimpulan yang dapat diambil, antara lain:

1. Madrasah merupakan lembaga pendidikan yang mengedepankan ilmu pengetahuan islam sebagai pokok pengajaran. Sebagai sekolah islam, madrasah perlu menunjukkan identitas keislamannya melalui aplikasi desain yang sesuai. Turki utsmaniyah dipilih sebagai symbol kejayaan islam.
2. Aplikasi konsep desain islami dengan nuansa turki utsmaniyah dapat diterapkan pada elemen ruang seperti dinding, plafon, detail jendela, detail pintu, desain furnitur ruang dan elemen estetis. Aplikasi desain tersebut dapat diambil dari konsep warna dan bentukan khas turki utsmaniyah.

\section{B. Saran}

Saran yang dapat diberikan dari penelitian ini adalah perlunya memperbanyak kajian tentang madrasah dan perilaku penggunanya sehingga diketahui permasalahan dan kebutuhan desain pada bangunan dan interior bangunan. Dengan begitu, penerapan desain yang diaplikasikan pada ruang tidak hanya berfungsi sebagai hiasan atau elemen estetis tetapi juga memiliki fungsi lain yang sesuai dengan kebutuhan.

\section{DAFTAR PUSTAKA}

[1] Effendi, Yusuf. April. 2010. Pondok Pesantren, Madrasah dan Sekolah, (https://yusufeff84.wordpress.com/2010/04/13/pondok-pesantrenmadrasah-dan-sekolah/).

[2] Idrus Irnawati, dkk. 2016. Intensitas Pencahayaan Alami Ruang Kelas Sekolah Dasar di Kota Makassar. Universitas Hassanudin Makassar, Simpusium Nasional RAPI XV.

[3] Milawati. Maret. 2016. Karya Arsitektur Turki Utsmani, (http://wawasansejarah.com/karya-arsitektur-turki-utsmani/).

[4] Saputra, Andika. Februari. 2013. Ideologi, Teori, Konsep dan Prinsip Arsitektur Masjid Utsmaniyah. Universitas Gadjah Mada Yogyakarta, LANTING Journal of Architecture Volume 2 No. 1.

[5] Syarif, Muhammad. April. 2012. Masjid Selimiye: Karya Termasyur dari Mimar Sinan, (http://www.republika.co.id/berita/duniaislam/khazanah/12/04/29/m37s75-masjid-selimiye-karya-termasyhurdari-mimar-sinan). 